\title{
PEER SUPPORT IN INDUSTRIAL ACTION: HOW COLLEAGUES' ANTICIPATED SOCIAL SUPPORT AFFECTS WILLINGNESS TO STRIKE*
}

\author{
Marieke J. Born and Agnes Akkerman ${ }^{\dagger}$
}

\begin{abstract}
This article studies how the support workers expect from colleagues for strike participation affects their willingness to participate in a strike. We formulate hypotheses on the effects of anticipated social support for participation as well as anticipated social support for nonparticipation. We include the potentially mediating effect of social identification and the social costs of (non-)participation. We test our hypotheses on survey data of 725 Dutch employees collected in 2010. Using structural equation modeling techniques, we find that the support for participation has a stronger positive effect on the willingness to strike than the support for nonparticipation has on the willingness to strike. In addition, our findings suggest that union membership substitutes the effect of social support of colleagues.
\end{abstract}

How is a worker's willingness to participate in a strike affected by the anticipated responses of colleagues to his or her strike participation? Ample empirical evidence has shown the importance of others in decisions to participate in protest (Klandermans 1984; van Zomeren and Spears 2009). Social rewards and sanctions by group members, or significant others, constitute an important selective incentive for overcoming the free rider problem in collective action (Olson 1965; Klandermans 1984; Janky and Takács 2010). While scholars acknowledge the importance of support for the opposite choice, that of nonparticipation (Klandermans 1984), the effect of this support has never been investigated as an independent incentive for participation. Disentangling social support for participation and nonparticipation is important, especially in polarized social contexts in which proponents and opponents of protest compete in mobilizing and demobilizing potential protesters. In a heavily polarized context, the social environment of potential protesters consists of significant others who fiercely favor participation as well as significant others who sternly oppose participation in a protest. We argue that in such polarized contexts, the effect of social determinants of participation - the normative motives - is less straightforward than commonly assumed in mobilization theory. The presence of proponents and opponents among the significant others means that there are social benefits (for this analysis, social support) and social costs associated with participation and also with nonparticipation. We need to understand the conditions under which support for and cost of participation outweighs the support for nonparticipation or vice versa. We therefore add the anticipated social support for nonparticipation and the anticipated social costs of both participation and nonparticipation to the current explanation of the effect of workers' social environment on strike participation.

In the empirical context of our study, that of labor strikes, such tensions between proponents and opponents of protest is extremely real. Both the union and its members likely make an appeal to an individual to participate, while the supervisor, management and, perhaps other colleagues simultaneously try to convince an individual to refrain from participation. Satisfying

\footnotetext{
* The authors acknowledge the financial support from the Netherlands Organization for Scientific Research (NOW) Conflict and Security Grants 432-08-022 and w07-01-202-005.

${ }^{\dagger}$ Marieke J. Born is policy advisor at the municipality of Apeldoorn (the Netherlands). Agnes Akkerman is Professor of Labor Market Institutions and Labor Relations at Department of Economics at the Nijmegen Institute for Management Research at Radboud University Nijmegen (the Netherlands). Direct all correspondence to a.akkerman@ fm.ru.nl.
} 
one side will result in disappointing and perhaps infuriating the other. We are especially interested in the effects of the ambiguous and diverting support from colleagues. Employees can support their colleagues' participation in a strike in different ways, such as by giving moral support and encouragement or by facilitating participation by jointly going to union meetings. Colleagues who oppose the strike may support their fellow nonstrikers by giving moral support or protection from potential (violent) harassment by strikers. Such support for nonparticipation are benefits that are missed out on when an employee decides to participate, while the social costs of (non)participation constitute any negative sanctioning of (non)participation, such as social exclusion, harassment, and more.

The empirical part of our study consists of two stages. First, we investigate the effects of social support and social costs associated with participation and nonparticipation, respectively. Second, we investigate the effect of union membership on the mechanisms we propose. The idea is that members are more likely to consider participation a duty for members, which may result in different effects of the different type of colleagues' responses. We test our hypotheses on a dataset of 725 workers, collected in 2010, using structural equation modeling.

\section{THEORY}

An individual's decision to participate in protest is the result of a costs and benefits analysis (e.g., Olson 1965; Klandermans 1984). In addition to monetary costs and benefits, and time, individuals also consider the social costs and benefits associated with participation and nonparticipation. Examples of social benefits are emotional support by significant others, such as family, friends, or supervisors (Klandermans 1984), while punishment, social exclusion, or other signals of social disapproval are considered social costs (Boyd and Richerson 1992; Price, Cosmides, and Tooby 2002). When the benefits outweigh the costs, people are more likely to participate in a protest.

Recent theoretical frameworks distinguish three motives in this cost-benefit analysis (e.g., see Simon, Loewy, Stürmer, Weber, Freytag, Habig, Kampmeier, and Spahlinger 1998; Stürmer and Simon 2004a; van Zomeren Postmes, and Spears 2008). First, individuals have a collective motive, which refers to the collective gains the protest aims to achieve, such as a wage increase. Collective gains can only be accomplished when all, or at least a critical part, of the group contributes. Without the contribution of all individual members, success of the protest becomes less likely. However, since collective gains are nonexclusive by definition, once obtained no one can be excluded from the benefits; hence, a freeriding problem occurs. To make participation more attractive, individuals need two additional motives: a reward motive and a normative motive. The reward motive refers to the individual benefits of participation, also known as selective incentives (Olson 1965). The normative motive consists of the expected reactions of significant others and the importance of the significant others for the individual, an element in the costbenefit analysis we consider further here.

\section{Social Identification as Origin for Normative Motives for Participation}

Normative motives for participation are strongly related to group norms on participation. The impact of group norms on an individual's decision depends on the extent to which an individual identifies with the group. Through social identification, norms within a group are formed, which tell group members what the appropriate behaviors are in certain situations (McAdam and Rucht 1993). Through identification with colleagues, guidelines about appropriate behavior in times of a looming strike exist among a group of workers. Defecting from the norms of one's group can have severe consequences for (future) relations with other group members (Klandermans, Rodriguez, and de Weerd: 2002). Thus, social identification with the group is considered one of the main predictors of participation (Klandermans 2004). However, this is only true under the assumption that group members are always in favor of going on strike. 
Group members (that is, colleagues) can either be in favor of or opposed to going on strike, and we argue that it is difficult to predict a positive or negative effect of social identification on willingness to strike. We do expect social identification to affect the social costs and social supports a worker anticipates. If a worker does not identify with the group that favors going on strike, he or she will not enjoy any social benefits from participating, nor suffer any social costs from nonparticipation. On the other hand, if a worker identifies strongly with both strikeopposing as well as strike-approving colleagues, participation will be associated with social benefits and cost. Thus, we formulate the following hypothesis:

Hypothesis 1: Identification with colleagues will affect willingness to participate through the social costs and benefits associated with (non)participation.

\section{Social Support for Participation and Nonparticipation}

Previous research on the effects of social support (Klandermans and Oegema 1987; Stürmer and Simon 2004b) finds that social support for participation increases the willingness to participate. Workers will assess whether their colleagues will support their decision to participate; it is this group of others with whom a worker will have to work on a daily basis that might attempt to influence the worker's decision to participate. Assuming that colleagues are the relevant significant others in the context of labor strikes, we formulate the following baseline hypothesis:

Hypothesis 2: Higher expected support for participation from colleagues will increase a worker's willingness to participate.

While the dominant focus of mobilization research is on social support in favor of participation (e.g. Klandermans 1984; Klandermans and Oegema 1987; Stürmer and Simon 2004b), some scholars acknowledge that social support for nonparticipation is likely to play a role as well (Klandermans 1984). Investigating the effect of a Dutch union's mobilization campaign on its members' willingness to participate in a strike, Klandermans (1984) analyzes the effect of the social support for participation as well as social support for nonparticipation. In his study, the support for nonparticipation is subtracted from the support for participating, thus implicitly treating the effects of social support for participation and social support for nonparticipation as equally important. However, can we safely assume that the impact of support of colleagues for participation in a strike equals the impact of the support of the employer for nonparticipation? We allow for the potentially distinct impact that social support for either behavior may have.

The potentially distinct impacts are especially important in the polarized context of a strike, as individuals may expect support for either decision from different people in their environment, with opposing views and opinions about participation. The question then arises whether the decision to participate requires an equal amount of social support as the decision not to participate in the strike. Following the inverse logic of hypothesis 2, we expect that the support of significant others for the decision not to participate will decrease the willingness to participate in a strike:

Hypothesis 3: Higher expected support for nonparticipation from colleagues will decrease a worker's willingness to participate.

\section{Social Cost of Participation and Nonparticipation}

The second element of the normative motive for participation is social cost. Similar to the bias of empirical research into the effects of social support, previous research into the effects of social cost of participation is also biased toward the norm to participate, and therefore focuses 
on the cost of nonparticipation (Thommes, Vyrastekova, and Akkerman 2015). The social costs of participation itself are seldom empirically investigated (but see Opp and Roehl 1990), although compelling in real life. Confrontations between strikers and those who continue working are quite common; moreover, once the strike is settled and workers need to work together again, social relations between former strikers and other employees sometimes proove difficult to reestablish (Thommes, Akkerman, Torenvlied, and Born 2014). Labor strikes are well known for creating divides between those workers who participate and those who continue to work (Francis 1985; Getman and Marshall 1993; Waddington, Dicks, and Critcher 1994; Getman 1999). These divisions sometimes persist long after the strike is settled. Although commonly nonstrikers are considered to be the free riders who risk social punishment, employees who continue to work appear to have reason to blame the strikers, too. First, colleagues may oppose a strike because it endangers relations with customers and clients, which in turn may endanger employment. Moreover, if employees strongly rely on their team members for their work and their income, those who remain working need to work harder to get their jobs done without the help of their striking team members (Thommes and Akkerman 2014; Born, Akkerman, and Thommes 2016;). It is therefore plausible to assume that workers will anticipate these social costs of participation as well and incorporate them in their decision. We expect that if workers expect social costs due to their participation, then their willingness to participate decreases:

Hypothesis 4: Higher expected social costs of participation will decrease a worker's willingness to participate.

Additionally, we restate the existing hypothesis about the effect of nonparticipation costs on the willingness to participate:

Hypothesis 5: Higher expected social costs of nonparticipation will increase a worker's willingness to participate.

The hypothesized relationships are summarized in figure 1. Both elements of normative motives are likely to be related. Employees who expect support from their colleagues for their decision are unlikely to expect to be sanctioned for this decision by the same colleagues. However, social support from colleagues does not exclude social cost inflicted by other peers (or even other significant others).

\section{The Role of Union Membership}

In times of a looming strike, most workers, union members and nonunion members alike, are generally the subject of mobilization campaigns by the union(s). Most research focuses on the effects of mobilization campaigns on members of a social movement (e.g. Kitts 2000; van Stekelenburg, Klandermans, and Van Dijk 2009). Union members may be more in favor of a strike and more willing to strike than their nonunion colleagues, because of the obligations these members feel towards their union (e.g., Martin and Sinclair 2001). Brunnschweiler, Jennings, and MacKenzie (2014) find that union members' participation in a strike is driven by emotional reasons rather than material or instrumental reasons. This finding suggests that union members also may weight social costs and social benefits of participation differently than nonunion members. For instance, members and nonmembers may differ in the costs they associate with (non)participation, caused by norms about solidarity during collective protest that are stronger for union members than for nonmembers. Therefore, we separately test our model for both members and nonmembers to explore if there is a difference between these two groups. 


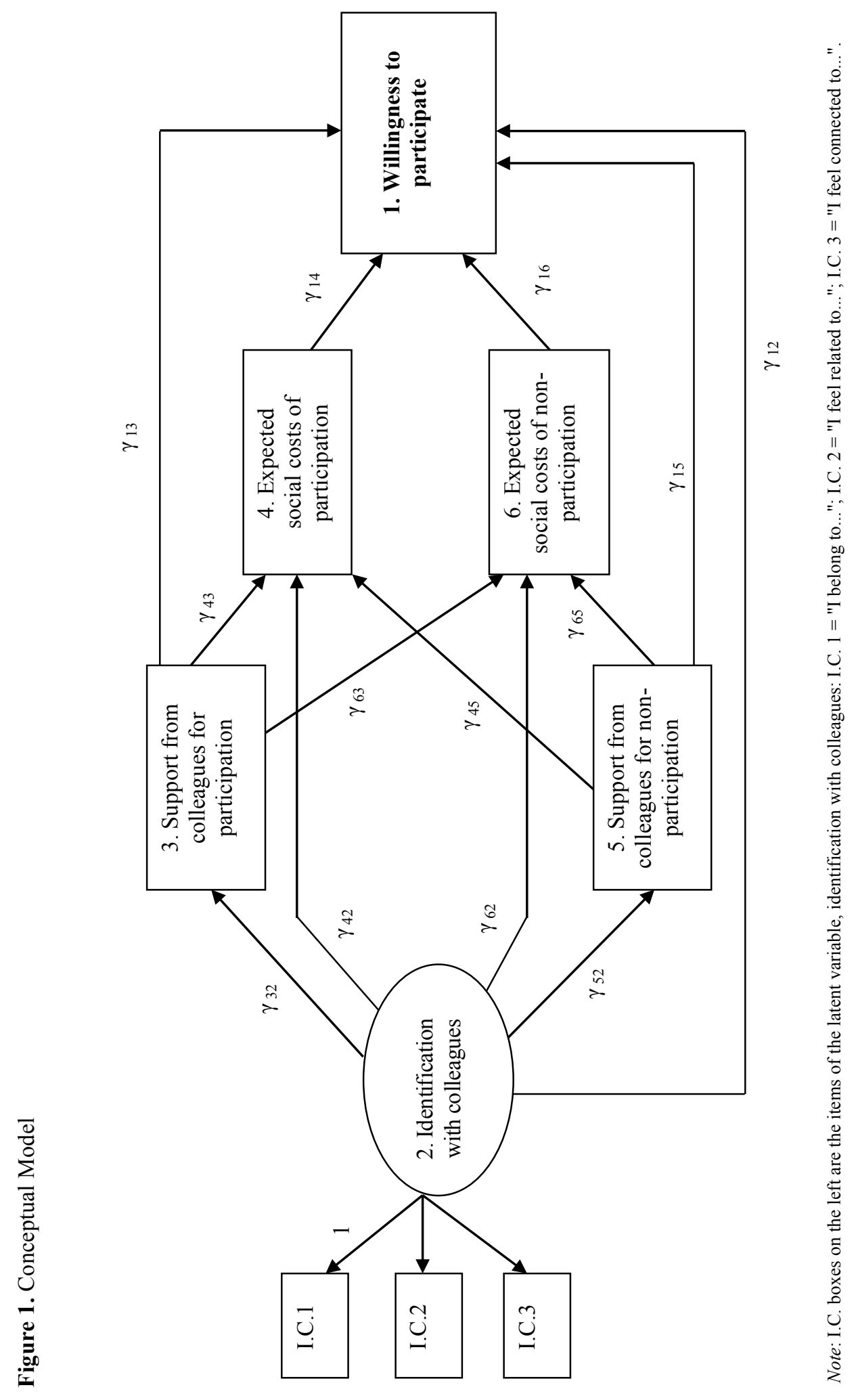




\section{METHODS}

We test our hypotheses on a pooled dataset of 725 respondents. This dataset consists of two samples of respondents. The first dataset was gathered in October 2010, via a web-based survey distributed to 800 panel members of the Christian Dutch Trade Union Confederation (CNV). This panel consisted of a representative set of randomly selected CNV members. Respondents who fully completed the questionnaire had the chance to win a 25 Euro voucher. ${ }^{1}$ Four hundred and sixty-eight members completed the questionnaire, for a response rate of $58 \%$. The second set was gathered in December 2010, via the same web-based survey sent out to 1,500 Dutch employees who were members of a panel that is surveyed periodically. For this sample, we applied a stratified sampling procedure based on gender, age, and region to enhance representativeness of these three criteria with respect to the Dutch workforce. Afterwards, this sample was rechecked on representativeness of gender, age, and region, after which a small weight factor was applied. Two hundred and fifty-seven respondents completed the questionnaire, for a response rate of $17 \%$. These two datasets were pooled, providing us with a dataset of 725 Dutch employees.

Of our respondents, $68.8 \%$ were male $(\mathrm{N}=494)$ and $30.5 \%$ were female $(\mathrm{N}=221)$. Ten respondents did not specify whether they were male or female $(1.4 \%)$. The average age of our respondents was 49.76 years $(\mathrm{SD}=11.66)$. Due to the combination of our two datasets, a large number of our respondents were members of the CNV trade union confederation $(65.9 \%$; $\mathrm{N}=$ 478). Additionally, $7.2 \%$ of the respondents were members of one of the FNV trade union confederations $(\mathrm{N}=52)$, while 18 respondents stated they were members of one of the other unions in the Netherlands (2.5\%). Finally, 177 respondents were not members of a union $(24.4 \%)$.

\section{Measurements}

The Dependent Variable. The main dependent variable is the willingness to participate in a future strike for a wage increase, because in the Netherlands, most strikes concern disputes about wages (van der Velden 2000). The respondents were asked to rate their willingness on a Likert scale, ranging from 1 ("not at all") to 5 ("highly likely"). Although some authors have criticized the use of intended participation in a hypothetical future strike to measure individual willingness to participate (Gallagher and Strauss, 1991; McClendon and Klaas 1993), three important arguments advocate the use of intended participation. First, measuring actual participation has proven complicated, as it is difficult to predict strikes and to gain access to strikers (Klandermans and Smith 2002). Second, when investigating actual participants, it is difficult to assess how the expected costs and benefits affected their participation willingness in hindsight. Finally, the theory of reasoned action (Fishbein and Ajzen 1975) argues that intentions are congruent with actions and that intended participation is the best predictor of actual participation (Kelloway 1998). Hence, we argue that willingness to participate is the most valid measure available for the purpose of the present study.

Explanatory Variables. Social identification with colleagues was measured as a scale of three items: "I belong to ...", "I feel related to ...", and "I feel connected to ..." (see the three I.C. boxes on the left in figure 1). We specifically asked respondents to rate identification with their colleagues "in times of a looming conflict about a collective agreement." The three items were rated on a five-point Likert scale and validated by previous research on identification with groups (van Stekelenburg, Klandermans, and Van Dijk 2011; van Zomeren, Spears, Fischer, and Leach 2004; van Zomeren, Spears, and Leach 2008). We measured social identification with direct colleagues and with other colleagues. For the purposes of the analyses in this manuscript we added the scores of both scales into one scale, named "social identification with colleagues", for which the scores can range from 0 to 30 . To assess the validity of our social identification scale, we performed confirmatory factor analyses in AMOS 20. The individual item reliability as well as the composite reliability was gained from the factor analysis. Generally, an item reliability of .5 and a composite reliability of .6 is required (Bagozzi and Yi 1988). Social 
identification with colleagues met these standards with the items' reliability ranging from .710 to .897 and with a composite reliability of .915 .

Social support for participation was measured with one item, which asked, "If you would participate in a strike, how would your colleagues react?" Respondents had to rate this item on a five-point Likert scale from 1 ("They would not support my decision to participate at all") to 5 ("They would support my decision to participate very much"). For social support for nonparticipation, we used the item, "If you would not participate in a strike, how would your colleagues react?" Once again, respondents had to rate this item on a five-point Likert scale.

The expected social cost of participation was measured with one item. Respondents were asked whether they expected that their participation in collective action in the future would lead to negative consequences for the relationship with their colleagues. Respondents rated these negative consequences on a five-point Likert scale. Expected social costs of nonparticipation was measured with one item. Respondents were asked to rate to what extent they agreed with the following statement: "Colleagues who did not participate could be confronted about their behavior by other colleagues". Respondents had to rate how much they agreed with the statement on a five-point Likert scale.

Table 1 provides the descriptive statistics, reported separately for union members and nonunion members in addition to the overall descriptive statistics and the correlations between the main variables. Table 1 allows for three observations. First, the mean scores of union members and nonunion members are significantly different with regard to the anticipated support for participation. The average anticipated support for participation is higher for nonunion members while the average anticipated social costs of nonparticipation and the average identification with colleagues are both higher for union members. Second, the willingness to participate correlates stronger with support for participation than with support for nonparticipation. This suggests that support in favor may indeed carry a different weight in the decision to participate than support for nonparticipation. Finally, the absence of significant correlations between social identification with colleagues and most of the other variables, especially willingness to participate, is noteworthy. Apparently, identification with colleagues is not very important for the decision to participate. This finding does not exclude, however, the importance of social identification with other actors, such as the union.

Table 1. Descriptive Statistics and Correlations of the Main Variable (S.D. in parentheses).

\begin{tabular}{|c|c|c|c|c|c|c|c|c|}
\hline & $\begin{array}{c}\text { Mean } \\
\text { Union } \\
\text { Members }\end{array}$ & $\begin{array}{l}\text { Mean } \\
\text { Nonunion } \\
\text { Members }\end{array}$ & $\begin{array}{c}\text { Overall } \\
\text { Mean }\end{array}$ & 1 & 2 & 3 & 4 & 5 \\
\hline Willingness to participate & $\begin{array}{c}2.57 \\
(1.48)\end{array}$ & $\begin{array}{c}2.76 \\
(1.48)\end{array}$ & $\begin{array}{c}2.62 \\
(1.48)\end{array}$ & & & & & \\
\hline Support for participation & $\begin{array}{c}3.10 \\
(1.23)\end{array}$ & $\begin{array}{l}3.43 \\
(1.14) * * *\end{array}$ & $\begin{array}{c}3.18 \\
(1.21)\end{array}$ & $.381 * *$ & & & & \\
\hline Support for nonparticipation & $\begin{array}{c}2.80 \\
(1.03)\end{array}$ & $\begin{array}{c}2.91 \\
(1.02)\end{array}$ & $\begin{array}{c}2.82 \\
(1.02)\end{array}$ & $-.148 * *$ & $-.155^{* *}$ & & & \\
\hline $\begin{array}{l}\text { Expected social costs of } \\
\text { participation }\end{array}$ & $\begin{array}{c}1.99 \\
(1.15)\end{array}$ & $\begin{array}{c}2.13 \\
(1.19)\end{array}$ & $\begin{array}{c}2.02 \\
(1.16)\end{array}$ & -.077 & $-.201 * *$ & $121 * *$ & & \\
\hline $\begin{array}{l}\text { Expected social costs of } \\
\text { nonparticipation }\end{array}$ & $\begin{array}{c}2.85 \\
(1.37)\end{array}$ & $\begin{array}{l}2.43 \\
(1.24) * * *\end{array}$ & $\begin{array}{c}2.73 \\
(1.35)\end{array}$ & $.272 * *$ & $.179^{* *}$ & $-.110 * *$ & -.030 & \\
\hline Identification with colleagues & $\begin{array}{l}22.88 \\
(5.55)\end{array}$ & $\begin{array}{l}21.26 * * * \\
(6.53)\end{array}$ & $\begin{array}{l}22.48 \\
(5.86)\end{array}$ & -.012 & $.094 *$ & .092 & .013 & -.040 \\
\hline
\end{tabular}

Bold indicates significant differences in means (using independent t-test) between union members $(\mathrm{N}=482)$ and non-

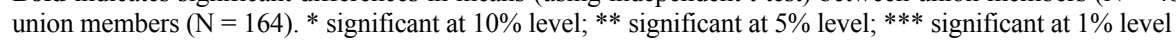




\section{RESULTS}

To test our model, we used structural equation modeling. We use the measures of overall fit to assess if the hypothesized model is a good indicator of the structures underlying the observed data. First, we checked the overall fit of our model. The chi-square of our model is significant $\left(\chi^{2}(12)=26.860 ; p=.008\right)$, and a significant chi-square could indicate a poor fit. However, a large sample such as ours is likely to create a significant chi-square (Kelloway 1995), so we investigated the model fit further. The chi-square/degrees of freedom ratio of the full model is below three (ratio $=2.24$ ), which indicates a satisfactory fit (Hooper, Coughlan, and Mullen 2008). The Goodness-of-Fit index (GFI) is a descriptive overall measure of fit. Usually, a threshold of .9 is suggested for the GFI (Bagozzi and Yi 1988; Hooper et al. 2008). The GFI of our model is .990 and thus meets the required standards. Second, we consider the rootmean-square error of approximation (RMSEA), which is less dependent on sample size (Widaman and Thompson, 2003). Values close to or below 0.06 indicate a good fit of the model (Hu and Bentler 1999). The RMSEA of our model is .044. Furthermore, we consider the normed fit index (NFI) and the comparative fit index (CFI). The suggested cutoff point for NFI and CFI is 0.95 (Hu and Bentler 1999; Hooper et al. 2008). Both these indices of our model meet the required standards $(\mathrm{NFI}=.985$; CFI $=.992)$. Therefore, we concluded that this model fits the data well and we can use the model to test our hypotheses.

When we consider the direct effects in the model, we find that social identification significantly increases expected support for participation (standardized estimate $=.105 ; p<$ .01 ) and significantly increases expected support for nonparticipation (standardized estimate $=$ $.101 ; p<.05)$. We find no significant direct effect for identification with col-leagues on willingness to participate. Testing our first hypothesis, which states that identification with colleagues will affect willingness to participate indirectly through the expected costs and benefits of participation and nonparticipation, we find support for the indirect effects of social identification via expected support for participation (estimate $=.029$; S.E. $=.012 ; p<.05)^{2}$ and expected support for nonparticipation (estimate $=-.006$; S.E. $=.004 ; p<.05$ ). These results are a first indication that social identification indeed affects the support workers expect from their colleagues and as such affects their participation willingness. We found no effects of social identification on participation willingness via expected costs of participation and expected costs of nonparticipation.

Table 2. Parameter Values of the Conceptual Model

\begin{tabular}{|c|c|c|c|c|}
\hline Parameter & Relation & $\begin{array}{c}\text { Parameter value } \\
\text { (standardized) }\end{array}$ & S.E. & $\begin{array}{c}\text { Critical } \\
\text { ratio } \\
\end{array}$ \\
\hline$\gamma_{32}$ & Identification - support participation & $.105 * * *$ & .028 & 2.577 \\
\hline$\gamma_{42}$ & Identification - cost participation & .011 & .026 & .273 \\
\hline$\gamma_{43}$ & Support participation- cost participation & $-.189 * * *$ & .037 & -4.833 \\
\hline$\gamma_{45}$ & Support nonpart- cost participation & $.091 * *$ & .044 & 2.338 \\
\hline$\gamma_{52}$ & Identification- support nonpart & $.101 * *$ & .023 & 2.482 \\
\hline$\gamma_{62}$ & Identification - cost nonpart & -.047 & .030 & -1.170 \\
\hline$\gamma_{63}$ & Support part - cost nonpart & $.173 * * *$ & .043 & 4.407 \\
\hline$\gamma_{65}$ & Support nonpart - cost nonpart & $-.079 * *$ & .052 & -2.006 \\
\hline$\gamma_{12}$ & Identification - willingness to participate & -.029 & .031 & -.782 \\
\hline$\gamma_{13}$ & Support participation - willingness to participate & $.340 * * *$ & .045 & 9.133 \\
\hline$\gamma_{14}$ & Cost participation - willingness to participate & .005 & .046 & .144 \\
\hline$\gamma_{15}$ & Support nonpart- willingness to participate & $-.071 * *$ & .052 & -1.962 \\
\hline$\gamma_{16}$ & Cost nonpart - willingness to participate & $.203 * * *$ & .040 & 5.564 \\
\hline
\end{tabular}

* significant at $10 \%$ level; $* *$ significant at $5 \%$ level; *** significant at $1 \%$ level 
Hypothesis 2 stating that higher expected support for participation increases a worker's willingness to participate was confirmed (standardized regression weight $=.340, p<.01$ ). This finding is in line with previous empirical research (Klandermans 1984; Klandermans and Oegema 1987; Stürmer and Simon 2004b) and indicates that when a worker expects support from colleagues should she choose to participate in a strike, she is more willing to participate in this strike. When workers expect support for not participating from their colleagues, their willingness to participate decreases (standardized estimate $=-.071 ; p=.05$ ), which confirms hypothesis 3 . This finding indicates that both forms of support do affect the worker's willingness to participate. However, the effects differ in size. Hypothesis 4 that higher expected social costs of participation decrease a worker's willingness to participate, could not be confirmed; we found no significant effect of the expected social costs of participation on willingness to participate. However, we did find support for hypothesis 5, which states that higher expected social costs of nonparticipation increase the willingness to participate (standardized estimate $=$ $.203 ; p<.01)$. This indicates that when workers expect to be punished for nonparticipation, they are more likely to participate to avoid these costs, which confirms previous research (Francis 1985; Boyd and Richerson 1992; Price, Cosmides, and Tooby 2002; Akkerman, Born, and Torenvlied 2013).

Beyond the tests of hypotheses, we found that the expected support from col-leagues for participation decreases the expected social costs of participation (standardized regression weight $=-.189, \mathrm{p}<.01)$. Likewise, the expected support in favor of participation increases the costs of nonparticipation (standardized regression weight $=.173, \mathrm{p}<.01$ ). When support for not participating is expected, workers do expect higher social costs when they participate (standardized regression weight $=.091 ; p<.05$ ). We found significant results for the opposite as well: when workers expect more support for nonparticipation, they expect fewer costs of nonparticipation, e.g. freeriding (standardized regression weight $=-.079, \mathrm{p}<.05$ ).

\section{The Difference Between Union Members and Nonmembers}

The next step investigates whether social support has a different effect for union members than for nonmembers. For this, we compared the full model for union members and nonmembers. Once we included the moderator variable in our model, meaning we divided our sample into members and nonmembers, the RMSEA of our full model improved somewhat. The chi-square/degrees of freedom ratio of the full model is below 3 (ratio $=1.95)$, which indicates a good fit (Hooper et al. 2008). The other indices still met the required standards. When comparing samples of unequal sizes, as is the case in our analyses (members $=474$; nonmembers $=167$ ), the Tucker-Lewis index (TLI) should be considered (Byrne 1991). The cut-off point for this index is .90 . The TLI in our model is .970 and hence meets the required standards: $\left[\chi^{2}(24)=46.878 \mathrm{p}=.003 ;\right.$ GFI $\left..982 ; \mathrm{RMSEA}=.039 ; \mathrm{NFI}=.975 ; \mathrm{CFI}=.987 ; \mathrm{TLI}=.970\right]$.

To test for the moderator effect, the first step is to calculate the chi-square difference between a model in which the parameters are allowed to vary and a model in which all the parameters are restricted. This test investigates the null hypothesis that the moderator variable does not have any effect on our parameters. In our case, this null hypothesis is not rejected $\left(\Delta \chi^{2}\right.$ $=18.546 ; \Delta \mathrm{DF}=15 ; \mathrm{p}=.235)$. This means that the complete models do not differ; however, there might be differences between parameters. Next, we performed a hierarchical procedure (Steenkamp and Baumgartner 1998; Homburg and Giering 2001). The models compared are nested and hence the general model has one degree of freedom less than the restricted model. The chi-square value of the restricted model will therefore be higher than that of the general model (Homburg and Gierin 2001). A significant difference between the two models is found when the chi-square difference is higher that 2.17 at the $10 \%$ level, higher than 3.84 at the $5 \%$ level, and higher than 6.63 at the $1 \%$ level. Finding this difference indicates that the moderator has a significant effect on the parameters. The results of the moderator analysis are presented in table 3 on the following page. 
Table 3. Results of the Moderator Analysis

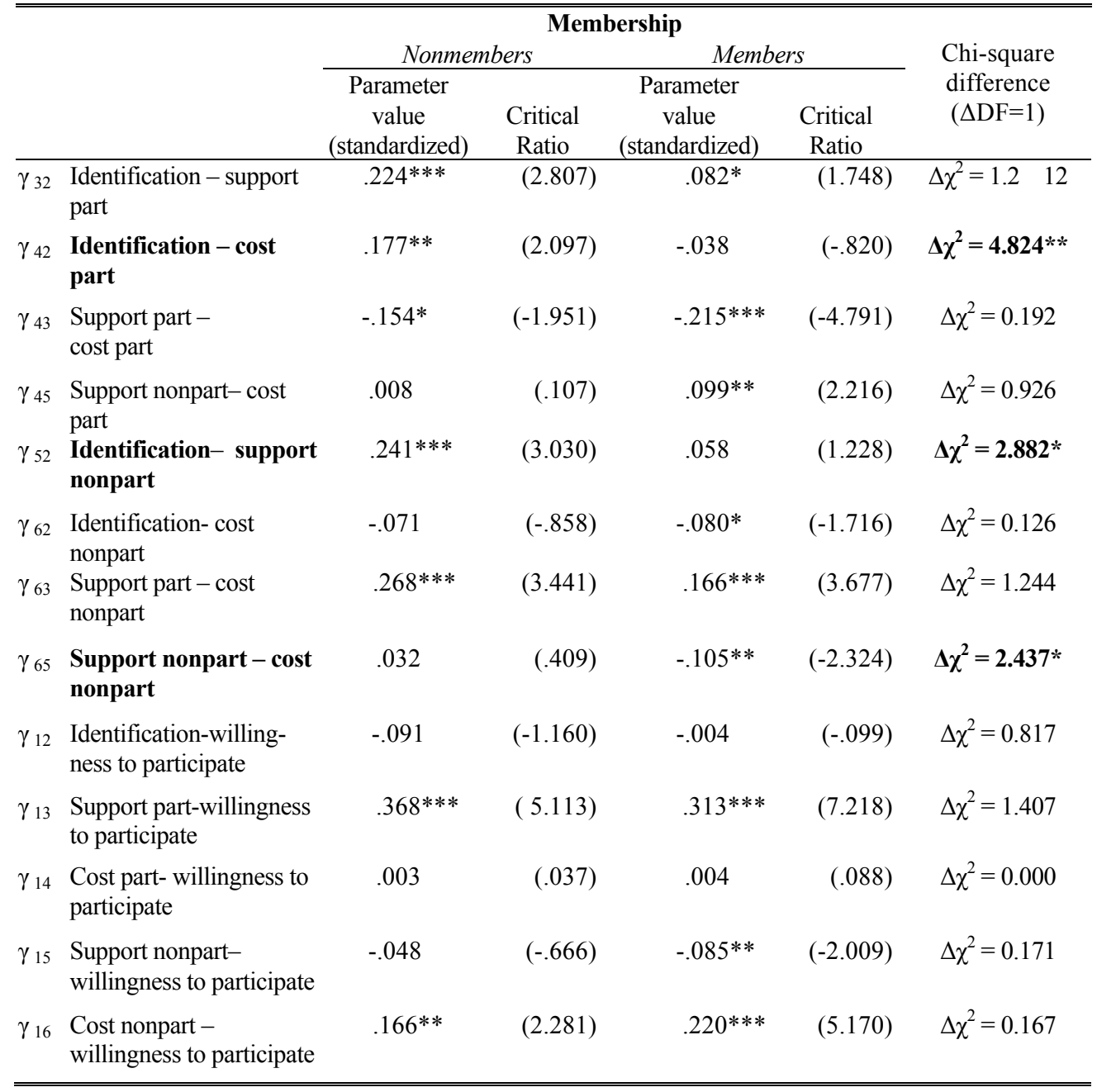

We found significant effects of union membership with respect to three of our parameters. The effect of identification with colleagues on expected social costs differs significantly $\left(\Delta \chi^{2}=4.824 ; p<.05\right)$ between union members and nonmembers. We did not find a significant effect for union members, but rather a positive significant effect for nonmembers (standardized estimate $=.177, p<.05$ ). Thus, identification with colleagues increases the effect on the anticipated social costs of participation for nonmembers, while it has no significant effect on the social cost of participation that union members anticipate. Moreover, a significant difference $\left(\Delta \chi^{2}=2.882 ; p<.10\right)$ was found for the effect of identification with colleagues on support for nonparticipation. For nonmembers, identification has a positive effect on expected support for nonparticipation (standardized regression weight $=$ $.241 ; p<.01$ ), while for union members this effect is absent. Apparently, identification with colleagues is less important for union members than it is for nonunion members.

Lastly, we found a significant difference $\left(\Delta \chi^{2}=2.437 ; p<.10\right)$ for the effect of expected support for nonparticipation on the expected costs of nonparticipation. For nonmembers, we find no significant effect. However, for members we find a significant negative effect (standardized regression weight $=-.105 ; p<.05$ ), implying that when the support for nonparticipation increases, the costs of nonparticipation decrease. 


\section{CONCLUSION AND DISCUSSION}

We investigated how willingness to participate in a strike is related to peer support. In times of a looming strike, one of the elements of workers' decision to participate is the social support of their colleagues for such a decision. We argued that workers also may receive support for not participating as well, and that each type of support may carry a different weight in the decision to participate.

Our statistical analyses produced three notable findings. The first concerns the effect of anticipated support and willingness to participate. The anticipated support in favor of participation is positively related to participation, whereas anticipated support for nonparticipation is negatively related to workers' willingness to participate. Although this finding may be not at all surprising, we did find substantive differences in the effect size of support for participation and that for nonparticipation: the willingness to participate in a strike increases more with support for participation than it decreases when colleagues support nonparticipation. This means that, in the context of labor strikes, the appeals made by colleagues in favor of participation are more influential than the appeals of colleagues against participation. A possible explanation for this finding may be that anticipated support in favor of participation also increases the perceived efficacy of the protest, which also leads to higher willingness to participate (Van Zomeren et al. 2004).

Second, we found interesting differences in the effect of identification with colleagues for union members and nonmember. Generally, identification with colleagues is positively related to both the support for participation and the support for nonparticipation. When we analyze these effects for members and nonmembers separately, we find that these positive effects of identification only hold for nonmembers. Apparently, union members do not need to identify with colleagues in order to anticipate support for their decision. An explanation for this could be that the union as a mobilizing actor serves as an agent for social support. If workers lack the support of the union, colleagues become important sources for social support. Thus, union members are less influenced by colleagues because of their access to and support from their union, with which they identify during a strike. This suggests that access to a union (or a social movement in general) substitutes the effect of the daily social environment, namely colleagues.

The third notable finding is the negative association between social support for nonparticipation and social costs of nonparticipation, which is only present for union members. This, combined with the finding that union members anticipate significantly higher costs of nonparticipation, suggests that union members perceive different responses from their social environment to nonparticipation. Membership to a union probably induces a felt norm of solidarity in participation, a norm that is not felt, or is perhaps not felt as much, by nonmembers. This normative pressure seems to be released by support for nonparticipation in the social environment of the union member.

Our research has two important limitations. One limitation is its oversampling of union members. Although we have no indication that this obscures our findings, in future research a more representative sample of membership is necessary. In particular, there could be significant differences between the willingness to participate in a strike among members of different unions.

Another limitation of our research is that we did not investigate nested employees, that is, employees in teams or organizations. Information on group norms, the decisions of colleagues, and other characteristics of team members was therefore not available. Especially when investigating the relationship between social support and willingness to participate, the specific social context, such as the dominant opinion of colleagues, may play a vital role.

Finally, our cross-sectional research design does not allow us to test the causal direction of the theoretical mechanism we propose. The statistical associations we found could therefore reflect different causal directions than proposed in the hypotheses. For example, the relation we found between social identification and anticipated social support for strike participation may imply that social identification causes more anticipated social support (as our theoretical model 
proposes), but this also may imply that anticipated support causes people to identify more with colleagues, even though such a reversed causal relation would refute common theoretical notions in social movement theory. Longitudinal designs, such as panel data, long-term case studies, and experimental designs, can help to overcome such methodological problems. Finally, the different effects of the social costs of participation and the social costs of nonparticipation may have been caused by measurement differences. ${ }^{3}$

\section{NOTES}

\footnotetext{
${ }^{1}$ Of the respondents, nine were randomly selected to receive a voucher (this represents $2 \%$ of the respondents). Respondents were not aware of the probability of winning the voucher.

${ }^{2}$ Unstandardized estimates, SE calculated with Sobel test.

${ }^{3}$ The item measuring the social cost of nonparticipation taps into expected confrontation. The latter could have caused a stronger framing compared to general and abstract negative consequences of the item tapping into the social cost of participation. Therefore, the difference in the framing of the two items may be responsible for the difference in effects and makes the comparison between the two more difficult.
}

\section{REFERENCES}

Akkerman, Agnes, Marieke J. Born, and R. Torenvlied. 2013. "Solidarity, Strikes, and Scabs: How Participation Norms Affect Union Members' Willingness to Strike." Work and Occupations 40(3): 250-80.

Bagozzi, Richard P., and Youjae Yi. 2000 "On the Evaluation of Structural Equation Models." Journal of the Academy of Marketing Science 16(1): 74-94.

Born, Marieke J, Agnes Akkerman and Kirsten Thommes. 2016. "Peer influence on protest participation: Communication and trust between co-workers as inhibitors or facilitators of mobilization." Social Science Research 56 :58-72.

Boyd, Robert, and Peter J. Richerson 1992. "Punishment Allows the Evolution of Cooperation (or Anything Else) in Sizable Groups." Ethology and Sociobiology 13(3): 171-195.

Brunnschweiler, Christa N., Colin Jennings, and Ian A. MacKenzie. 2014. "A Study of Expressive Choice and Strikes.” European Journal of Political Economy 34(??): 111-125.

Byrne, Barbara M. 1991. "The Maslach Burnout Inventory: Validating Factorial Structure and Invariance Across Intermediate, Secondary, and University Educators." Multivariate Behavioral Research 26(4): 583-605.

Fishbein, Martin, and Icek Ajzen. 1975. Belief, Attitude, Intention, and Behavior: An Introduction to Theory and Research. Reading, MA: Addison-Wesley.

Francis, Hywel. 1985. "The Law, Oral Tradition and the Mining Community." Journal of Law and Societ, 12(3: 267-71.

Gallagher, Daniel G., and George Strauss. 1991. "Union Membership Attitudes and Participation.” Pp. 139-174 in The State of the Unions, edited by Daniel G. Gallagher and Jack Fiorito. Madison WI: Industrial Relations Research Association.

Getman, Julius G. 1999. The Betrayal of Local 14. Ithaca, NY: Cornell University Press.

Getman, Julius G., and F. Ray Marshall. 1993. "Industrial Relations in Transition: The Paper Industry Example." Yale Law Journal 102(8): 1803-95.

Homburg, Christian, and Annette Giering. 2001. "Personal Characteristics as Moderators of the Relationship Between Customer Satisfaction and Loyalty: An Empirical Analysis.” Psychology and Marketing 18(1): 43-66.

Hooper, Daire, Joseph Coughlan, and Michael R. Mullen 2008. "Structural Equation Modelling: Guidelines for Determining Model Fit.” Electronic Journal of Business Research Methods 6(1): 53-60.

$\mathrm{Hu}$, Li-tze, and Peter M. Bentler. 1999. "Cutoff Criteria for Fit Indexes in Covariance Structure Analysis: Conventional Criteria versus New Alternatives.” Structural Equation Modeling 6(1): 1-55.

Janky, Béla, and Károly Takács. 2010. "Efficient and Inefficient Social Control in Collective Action." CEU Political Science Journal 5(3): 316-54. 
Kelloway, E. Kevin. 1995. "Structural Equation Modeling in Perspective." Journal of Organizational Behavior 16: 215-24.

-1998. Using Lisrel for Structural Equation Modeling: A Researcher's Guide. London: Sage.

Kitts, James A. 2000. "Mobilizing in Black Boxes: Social Networks and Participation in Social Movement Organizations." Mobilization 5(2): 241-57.

Klandermans, Bert. 1984. "Mobilization and Participation: Social-Psychological Expansions of Resource Mobilization Theory." American Sociological Review 49(5): 583-600.

- 2004. "The Demand and Supply of Participation: Social Psychological Correlates of Participation in Social Movements." Pp. in The Blackwell Companion to Social Movements, edited by David A. Snow, Sarah A. Soule, and Hanspeter Kriesi. Malden, MA: Wiley-Blackwell.

Klandermans, Bert, and Dirk Oegema. 1987. "Potentials, Networks, Motivations and Barriers: Steps Towards Participation in Social Movements.” American Sociological Review 52(4): 519-31.

Klandermans, Bert, Jose M. Mauro Rodriguez, and Marga de Weerd. 2002. "Identity Processes in Collective Action Participation: Farmers' Identity and Farmers' Protest in the Netherlands and Spain." Political Psychology 23(2), 235-51.

Klandermans, Bert, and Jackie Smith. 2002. "Survey Research: A Case for Comparative Designs.” Pp. 3-31 in Methods of Social Movement Research, edited by Bert Klandermans and Suzanne Staggenborg. Minneapolis: University of Minnesota Press.

Martin, James. E., and Robert Sinclair. 2001. "A Multiple Motive Perspective on Strike Propensities.' Journal of Organizational Behavior 22(4), 387-407.

McAdam, Doug, and Dieter Rucht. 1993. "The Cross-National Diffusion of Movement Ideas." Annuals of the American Academy of Political and Social Science 528(1): 56-74.

McClendon, John A., and Brian Klaas. 1993. "Determinants of Strike-Related Militancy: An Analysis of a University Faculty Strike." Industrial and Labor Relations Review 46(3): 560-73.

Olson, Mancur. 1965. The Logic of Collective Action: Public Goods and the Theory of Groups. Cambridge, MA.: Harvard University Press.

Opp, Karl D., and Wolgang Roehl. 1990. "Repression, Micromobilization, and Political Protest.” Social Forces 69(2): 521-47.

Price, Michael E., Leda Cosmides, and John Tooby. 2002. "Punitive Sentiment as an Anti-Free Rider Psychological Device." Evolution and Human Behavior 23(3): 203-31.

Simon, Bernd, Michael Loewy, Stefan Stürmer, Ulrike Weber, Peter Freytag, Corinna Habig, Claudia Kampmeier, and Peter Spahlinger. 1998. "Collective Identification and Social Movement Participation.” Journal of Personality and Social Psychology 74(3): 646-58.

Snow, David A., Rens Vliegenthart, and Catherine Corrigall-Brown. 2007. "Framing the French Riots: A Comparative Study of Frame Variation.” Social Forces 86(2): 385-415.

Steenkamp, Jan-Benedict E.M., and Hans Baumgartner. 1998. "Assessing Measurement Invariance in Cross-National Consumer Research.” Journal of Consumer Research 25(1): 78-90.

Stürmer, Stefan, and Bernd Simon. 2004a. "The Role of Collective Identification in Social Movement Participation: A Panel Study in the Context of the German Gay Movement." Personality and Social Psychology Bulletin 30(3): 263-77.

- 2004b. "Collective Action: Towards a Dual-Pathway Model." European Review of Social Psychology 15(1): 59-99.

Thommes, Kirsten and Agnes Akkerman. 2014. "Clean up your network-How a strike changed the social networks of a working team." Academy of Management Proceedings (Vol. 2014, No. 1, p. 13848).

Thommes, Kirsten, Agnes Akkerman, Rene Torenvlied, and Marieke Born. 2014. "The Dark Side of Solidarity: Social Norms and Social Relations in the Aftermath of Strikes." Industrial Relations Journal 45(4): 348-67.

Thommes, Kirsten, Jana Vyrastekova, and Agnes Akkerman. 2015. "Behavioral Spillovers from Freeriding in Multilevel Interactions." Journal of Behavioral and Experimental Economics 56: 78-87.

van der Velden, Sjaak. 2000. Stakingen in Nederland. (Strikes in the Netherlands). Amsterdam, Netherlands: Stichting beheer ISSG/NIWI.

van Stekelenburg, Jacqueline, Bert Klandermans and Wilco W. Van Dijk. 2009. "Context Matters: Explaining How and Why Mobilizing Context Influences Motivational Dynamics." Journal of Social Issues 65(4): 815-38.

. 2011. "Combining Motivations and Emotion: The Motivational Dynamics of Protest Participation.” Revista de Psicología Social 26(1): 91-104. 
van Zomeren, Martijn, Tom Postmes, and Russell Spears. 2008. "Toward an Integrative Social Identity Model of Collective Action: A Quantitative Research Synthesis of Three Socio-Psychological Perspectives." Psychological Bulletin 134(4), 504-35.

van Zomeren, Martijn, and Russell Spears. 2009. "Metaphors of Protest: A Classification of Motivations for Collective Action." Journal of Social Issues 65(2): 661-79.

van Zomeren, Martijn, Russell Spears, Agneta H. Fischer, and Colin W. Leach. 2004. "Put Your Money Where Your Mouth Is! Explaining Collective Action Tendencies Through Group-Based Anger and Group Efficacy." Journal of Personality and Social Psychology 87(5): 649-64.

Van Zomeren, Martijn, Russell Spears, and Colin W. Leach. 2008. "Exploring Psychological Mechanisms of Collective Action: Does Relevance of Group Identity Influence How People Cope with Collective Disadvantage?" British Journal of Social Psychology 47(2): 353-72.

Waddington, David, Bella Dicks, and Chas Critcher. 1994. "Community Responses to Pit Closure in the Post-Strike Era." Community Development Journal 29(2): 141-150.

Widaman, Keith F., and Jane S. Thompson. 2003. "On Specifying the Null Model for Incremental Fit Indices in Structural Equation Modeling." Psychological Methods 8(1): 16-37. 